\title{
Association between Chronic Kidney Disease and Depression
}

\author{
Adnan Bashir Bhatti*, Farhan Ali, Siddique A. Satti \\ Capital Development Authority (CDA) Hospita, Islamabad, Pakistan \\ Email: ${ }^{\text {dr.adnanbashir@gmail.com }}$
}

Received 25 March 2014; revised 15 April 2014; accepted 27 April 2014

Copyright (C) 2014 by authors and Scientific Research Publishing Inc.

This work is licensed under the Creative Commons Attribution International License (CC BY).

http://creativecommons.org/licenses/by/4.0/

\section{c) (i) Open Access}

\begin{abstract}
Background: Depression is relatively prevalent in chronic kidney disease (CKD) patients. Knowing the frequency of depression in these patients, the association with variables such as stage of disease, education, and income status may be helpful in devising strategies for better management. Methods: We examined 315 patients diagnosed with CKD presented in the outpatient and emergency department of medicine at Capital Hospital, Islamabad, Pakistan. Depression was diagnosed according to the Hamilton Depression Rating Scale of depressive episode. Results: In the dialysis group, $83.8 \%$ were depression positive, while in the pre-dialysis group only $61.3 \%$ of patients were given the same diagnosis $(P<0.05)$. A significant association was moreover found between depression and education status $(P<0.05)$, but not for income status. Conclusions: Considering the high incidence of depression in CKD patients, screenings should be routinely performed in order to identify and treat depression in its early stages for these patients.
\end{abstract}

\section{Keywords}

Chronic Kidney Disease, Depression, Education Status, Dialysis

\section{Introduction}

Chronic kidney disease (CKD) is a disease comprising of a wide spectrum of different pathophysiological processes, which is associated with abnormal renal function and a gradual degeneration of the glomerular filtration rate (GFR). The National Kidney Foundation's staging system divides the CKD patients in 5 stages according to GFR. Stage V is usually labelled as end stage renal disease (ESRD) [1].

The worldwide incidence of ESRD is increasing at a rate of about 7\% per annum, and the disease has been es-

*Corresponding author. 
timated to cost approximately 1.1 trillion dollars in medical expenditures worldwide [2]. The high incidence of chronic kidney disease in the Pakistani population is far from surprising, since the prevalence of diabetes and hypertension is very high for this population [3].

Previous studies have reported an overall mortality rate, 83\% higher for CDK patients than for the general population, and also found that cardiovascular disease was twice as common in CDK patients, compared to the healthy population. Due to the irreversible nature of this disease and the bleak prognoses associated with it, psychiatric disorders such as depression are commonly observed among CKD patients [4]-[6]. Depression may be triggered by a number of social, biologic, and psychological factors, and this has been reported to occur at any point during the progression of CKD [7]. Factors that affect the risk of depression include socioeconomic factors, and education status, the gender of the patient, and the presence/absence of symptoms such as disturbed liver function due to hepatitis, hypertension or hypoalbuminemia [8].

Although depression is frequently observed among renal dialysis patients, active detection and management (in form of psychotherapy and/or pharmacotherapy) are usually not part of the routine care for these patients [9]. To date, very few data are available regarding the frequency of depression in CKD and dialysis patients in Pakistan, and hence, we aimed to explore this.

\section{Materials and Methods}

\subsection{Overview}

A cross-sectional study was conducted in the emergency and outpatient medical department of Capital Hospital, Islamabad, Pakistan from January 1 to December 31, 2010. Permissions were granted from the concerned authorities of Capital Hospital Islamabad (Head of the Department of Medicine, Hospital Ethical Committee) before the initiation of the data collection phase.

\subsection{Data Collection}

By non-probability convenient sampling, 315 patients with diagnosed CKD (according to K/DQOI of the National Kidney Foundation of USA criteria) were included in the study.

Verbal consent was taken from all the patients after explaining the nature and purpose of the study at the beginning of the study. To minimize bias, all patients were handled by the same physician. After identification of patients with CKD, a detailed history was taken for diagnosis and fulfilment of the required selection criteria.

\subsection{Tools}

Information was collected using structured proforma. Demographic and clinical data were recorded, including patient history of diabetes mellitus, hypertension, glomerular diseases and interstitial disease. The Kidney Disease Outcome Quality Initiative (K/DOQI) guidelines by the National Kidney Foundation were used to stage CKD into five stages (Pre dialysis-CKD: Stages 2 - 4; Dialysis-CKD: Stage 5) based on the estimated glomerular filtration rate (eGFR). eGFR measurement was done by Cockcroft Gault formula, as follows:

$$
\text { Creatinine clearance }\left(\mathrm{C}_{\mathrm{Cr}}\right)=140-\operatorname{AGE} \times \text { weight }(\mathrm{kg}) / \text { Plasma Creatinine }\left(\mathrm{P}_{\mathrm{Cr}}\right) \times 72 \text {. }
$$

For females, the creatinine clearance was multiplied by 0.85 due to generally lower percentages of muscle mass compared to males. The diagnosis and severity of depression was made according to the Hamilton Depression Rating Scale of depressive episodes. Patients were graded as: no depression (score 0 - 7); mild depression (8 - 17); moderate depression (18 - 25); and severe depression (>25). Each item was read out loud by the physician to the patient, and the symptoms were marked according to the response. To supplement this, the Urdu version of the Hamilton Depression Rating Scale (H.D.R.S) was used.

\subsection{Data Analysis}

The statistical package for social sciences (SPSS, version 13.0, Chicago, IL) was used to enter and analyse the data. Mean values, standard deviations, frequencies and percentages were calculated. Chi square test was used to compare the frequency of depression between the two groups (Pre-dialysis and dialysis). A P-value $<0.05$ was considered significant. 


\subsection{Exclusion Criteria}

Patients aged less than 18 years or more than 90 years; patients already receiving treatment for depression; patients with chronic medical illness; patients with somatic symptoms of uraemia; and patients with other psychiatric diseases were excluded from the study.

\section{Results}

Out of a total of 315 patients enrolled in the study, 204 (64.76\%) patients were in dialysis group and 111 (35.24\%) were in pre-dialysis group. In the pre-dialysis group, 52 patients were male, with a mean age $( \pm \mathrm{SD})$ of 56.37 years \pm 17.07 , and 59 were female, with a mean age ( \pm SD) of 49.36 years \pm 19.17 . In the dialysis group, there were 106 males and 98 females, with a mean age $( \pm S D)$ of 49.49 years \pm 17.47 and 44.17 years \pm 17.83 , respectively (Table 1$)$.

$30.5 \%$ of all patients belonged to the low income group; $38.1 \%$ of patients belonged to middle income group; and $31.4 \%$ of patients belonged to the high income group (Table 2). In total, 117 (37.1\%) patients had no formal education; 76 (24.1\%) had less than, or equal to, eight years of school education; 57 (18.1\%) had greater than eight years but less than, or equal to, ten years of education; $52(16.5 \%)$ had greater than ten years education with a less than, or equal to, graduate level education; and 13 (4.1\%) had a postgraduate level of school education.

In the dialysis group, depression was present in 171 (83.8\%) patients, whereas 33 (16.2\%) patients showed no signs of depression. In the pre-dialysis group, depression was present in 68 cases (61.3\%; Table 3). In the lowincome group, 80 patients (83.3\%) were diagnosed with depression. For the middle-income group, this number was 87 (72.5\%), and for the high-income group, 72 patients (72.7\%) had depression, as shown in Table 4.

Depression was present in 80 (68.4\%) patients with no formal education and in 61 (80.3\%) of patients belonging to the middle or less education group. The middle to matric education group had 45 (78.9\%) cases of depression, whereas the matric to graduation groups had 46 (88.5\%) cases of depression. and the post graduation group had 7 (53.8\%) cases (Table 5).

\section{Discussion}

There is increasing evidence supporting a role for psychosocial factors such as depression, anxiety, and perceived social support, in the pathophysiology of various chronic diseases, including CKD, where depressive disorders have been found to be associated with an increased risk of mortality, and poor health-related quality of life [10]. We here used the Hamilton Depression Rating Scale to diagnose the different stages of depression. The Hamilton Depression Rating Scale is one of many ways to stage depression, and has recently been shown to be a

Table 1. Gender and age of CKD patients.

\begin{tabular}{ccccc}
\hline & Pre-dialysis (Stage II-IV) & Mean Age \pm SD (years) & Dialysis (Stage V) & Mean Age \pm SD (years) \\
\hline Male & $52(46.85 \%)$ & $56.37 \pm 17.07$ & $106(51.96 \%)$ & $49.49 \pm 17.47$ \\
Females & $59(53.15 \%)$ & $49.36 \pm 19.17$ & $98(48.04 \%)$ & $44.17 \pm 17.83$ \\
Total & $111(100 \%)$ & $52.64 \pm 18.86$ & $204(100 \%)$ & $47.20 \pm 17.74$ \\
\hline
\end{tabular}

Table 2. Patients according to income status.

\begin{tabular}{ccccc}
\hline Income & Frequency & Percentage (\%) & Valid Percentage (\%) & Cumulative Percentage (\%) \\
\hline Low $^{1}$ & 96 & 30.5 & 30.5 & 30.5 \\
Middle $^{2}$ & 120 & 38.1 & 38.1 & 68.6 \\
High $^{3}$ & 99 & 31.4 & 31.4 & 100.0 \\
Total & 315 & 100.0 & 100.0 \\
\hline
\end{tabular}

${ }^{1}$ Low income was identified as $<10,000$ PKR per month; ${ }^{2}$ Middle income was identified as 10,000 - 25,000 PKR per month; ${ }^{3}$ High income was identified as $>25,000$ PKR per month. 
Table 3. Association of different stages of depression with stages of CKD (dialysis and pre-dialysis groups).

\begin{tabular}{cccc}
\hline $\begin{array}{c}\text { Stages of depression } \\
\text { (Hamilton Depression Rating Scale) }\end{array}$ & Pre Dialysis & Dialysis & $P$-Value \\
\hline No depression & $43(38.7 \%)$ & $33(16.2 \%)$ & \\
Mild depression & $2(1.8 \%)$ & $11(5.4 \%)$ & $<0.001^{1}$ \\
Moderate depression & $6(5.4 \%)$ & $20(9.8 \%)$ & $140(68.6 \%)$ \\
Severe depression & $60(54.1 \%)$ & $204(100.0 \%)$ \\
\hline
\end{tabular}

${ }^{1}$ Absent vs. present depression.

Table 4. Association of different stages of depression with different group of income status.

\begin{tabular}{|c|c|c|c|c|c|}
\hline Stages of depression & Low income ${ }^{1}$ & Middle income $^{2}$ & High income $^{3}$ & Total & $P$-Value \\
\hline No depression & $16(16.7 \%)$ & $33(27.5 \%)$ & 27 (27.3\%) & $76(24.1 \%)$ & \\
\hline Mild depression & $10(10.4 \%)$ & $5(4.2 \%)$ & $2(2.0 \%)$ & & \\
\hline Moderate depression & $12(12.5 \%)$ & $2(1.7 \%)$ & $10(10.1 \%)$ & 239 (75.9\%) & $0.122^{4}$ \\
\hline Severe depression & $58(60.4 \%)$ & $80(66.7 \%)$ & $60(60.6 \%)$ & & \\
\hline Total & 96 (100.0\%) & 120 (100.0\%) & 99 (100.0\%) & 315 (100.0\%) & \\
\hline
\end{tabular}

${ }^{1}$ Low income was identified as $<10,000$ PKR per month; ${ }^{2}$ Middle income was identified as 10,000 - 25,000 PKR per month; ${ }^{3}$ High income was identified as $>25,000$ PKR per month; ${ }^{4}$ Absent vs. present depression.

Table 5. Association of different stages of depression with education status.

\begin{tabular}{|c|c|c|c|c|c|c|c|}
\hline Stages of depression & $\begin{array}{l}\text { No formal } \\
\text { education }\end{array}$ & Middle or less & $\begin{array}{l}\text { Middle to } \\
\text { matric }\end{array}$ & $\begin{array}{l}\text { Matric to } \\
\text { graduation }\end{array}$ & Post graduation & Total & $P$-Value \\
\hline No depression & 37 (31.6\%) & 15 (19.7\%) & $12(21.1 \%)$ & $6(11.5 \%)$ & $6(46.2 \%)$ & $76(24.1 \%)$ & \\
\hline Mild depression & $5(4.3 \%)$ & $1(1.3 \%)$ & $3(5.3 \%)$ & 2 (3.8\%) & $1(7.7 \%)$ & & \\
\hline Moderate depression & $10(8.5 \%)$ & $5(6.6 \%)$ & $2(3.5 \%)$ & $5(9.6 \%)$ & $1(7.7 \%)$ & 239 (75.9\%) & $0.013^{1}$ \\
\hline Severe depression & $65(55.6 \%)$ & 55 (72.4\%) & $40(70.2 \%)$ & 39 (75.0\%) & $5(38.5 \%)$ & & \\
\hline Total & 117 (100.0\%) & 76 (100.0\%) & 57 (100.0\%) & 52 (100.0\%) & $13(100.0 \%)$ & 315 (100.0\%) & \\
\hline
\end{tabular}

${ }^{1}$ Absent vs. present depression.

valid alternative to these other methods [11].

Similar results to what we found in this study have recently been reported by Hung et al. (2011), who explored the relationship between depression and demographic, socio-economic and clinical variables in CKD patients [12]. In another study, Wuerth et al. (2003) screened chronic peritoneal dialysis (PD) patients from July 1997 to October 2002, using the Beck Depression Inventory questionnaire. Based on the Hamilton Depression Scale and Standard Diagnostic and Statistical Manual of Mental Disorders criteria, 87\% (comparable to 83.8\% in our study) of their patients were diagnosed as being clinically depressed [13].

Watnick et al. (2003) showed that symptoms of depression were frequently observed at the early stages of dialysis treatment. However, they also noted that despite a high prevalence, treatment for the depression was rarely prescribed, even for patients described as having moderate-severe depression [14].

In two studies consisting of 210 and 380 peritoneal dialysis patients, scores consistent with a possible diagnosis of clinical depression were observed in $42 \%$ and $49 \%$, respectively. Out of the patients who agreed to further testing, $87 \%$ and $84 \%$, respectively, were diagnosed with clinical depression based on standard psychiatric criteria [15] [16].

Hedayatti et al. (2009) found in their study that 1 in 5 patients with CKD had experienced at least one major 
depressive episode, and that, for patient with late-stage CKD, there was an independent association between depression and poor survival outcome [17]. Hence, we suggest, as they also concluded, that, given the high prevalence of depression in CKD patients, routine screenings should be performed.

Lastly, another study also showed that depression correlated with a considerably increased risk of death in CKD patients [18]. However, during the course of our study, no patients died, and we were hence unable to draw any conclusions regarding the correlation between CKD, depression and patient survival.

\section{Conclusion}

In summary, we here examined 315 Pakistani patients with CKD for signs of depression, and for any associations between depression and education status and income. We found that the frequency of depression was significantly higher in the dialysis group and was significantly associated with education status, with patients with higher levels of education showing a lower frequency of depression $(P<0.05)$. No association was found between depression and income status in this study. We conclude that given the high prevalence of depression in CKD patients, screenings should be routinely performed in order to identify and treat depression in its early stages for these patients.

\section{References}

[1] Bargman, J.M. and Skorecki, K. (2008) Chronic Kidney Disease. In: Fauci, A.S., Braunwald, E., Kasper, D.L., Hauser, S.L., Eds., Harrison's Principles of Internal Medicine, Mc Graw Hill, 1761-1771.

[2] Lysaght, M.J. (2002) Maintenance Dialysis Population Dynamics: Current Trends and Long-Term Implications. Journal of the American Society of Nephrology, 13, S37-S40.

[3] Tamizuddin, S. and Ahmed, W. (2010) Knowledge, Attitude and Practices Regarding Chronic Kidney Disease and Estimated GFR in a Tertiary Care Hospital in Pakistan. Journal Pakistan Medical Association, 60, 342-346.

[4] Bossola, M., Ciciarelli, C., Stasio, D., et al. (2010) Correlates of Symptoms of Depression and Anxiety in Chronic Hemodialysis Patients. General Hospital Psychiatry, 32, 125-131.

http://dx.doi.org/10.1016/j.genhosppsych.2009.10.009

[5] Chilcot, J., Wellsted, D. and Farrington, K. (2010) Depression in End-Stage Renal Disease: Current Advances and Research. Seminars in Dialysis, 23, 74-82. http://dx.doi.org/10.1111/j.1525-139X.2009.00628.x

[6] Cukor, D., Cohen, S.D., Peterson, R.A., et al. (2007) Psychosocial Aspects of Chronic Disease: ESRD as a Paradigmatic Illness. Journal of the American Society of Nephrology, 18, 3042-3055. http://dx.doi.org/10.1681/ASN.2007030345

[7] Zalai, D.M. and Novak, M. (2008) Depressive Disorders in Patients with Chronic Kidney Disease. Prim Psychiatry, 15, 66-72.

[8] Anees, M., Barki, H., Masood, M., Mumtaz, A. and Kausar, T. (2008) Depression in Hemodialysis Patients. Pakistan Journal of Medical Sciences, 24, 560-565.

[9] Chilcot, J., Wellsted, D. and Farrington, K. (2008) Screening for Depression While Patients Dialyse: An Evaluation. Nephrology Dialysis Transplantation, 23, 2653-2659. http://dx.doi.org/10.1093/ndt/gfn105

[10] McKercher, C., Sanderson, K. and Jose, M.D. (2013) Psychosocial Factors in People with Chronic Kidney Disease Prior to Renal Replacement Therapy. Nephrology, 18, 585-591. http://dx.doi.org/10.1111/nep.12138

[11] Leentjens, A.F.G., Dujardin, K., Marsh, L., et al. (2011) Anxiety Rating Scales in Parkinson's Disease: A Validation Study of the Hamilton Anxiety Rating Scale, the Beck Anxiety Inventory, and the Hospital Anxiety and Depression Scale. Movement Disorders, 26, 407-415. http://dx.doi.org/10.1002/mds.23184

[12] Hung, K.C., Wu, C.C. and Chen, H.S. (2001) Serum IL-6, Albumin and Comorbidities Are Closely Correlated with Symptoms of Depression in Patients on Maintenance Haemodialysis. Nephrology Dialysis Transplantation, 26, 658664. http://dx.doi.org/10.1093/ndt/gfq411

[13] Wuerth, D., Finkelstein, S.H., Kliger, A.S., et al. (2003) Chronic Peritoneal Dialysis Patients Diagnosed with Clinical Depression: Results of Pharmacologic Therapy. Seminars in Dialysis, 16, 424-427. http://dx.doi.org/10.1046/j.1525-139X.2003.16094.x

[14] Watnick, S., Kirwin, P., Mahnensmith, R. and Concato, J. (2003) The Prevalence and Treatment of Depression among Patients Starting Dialysis. American Journal of Kidney Disease, 41, 105-110. http://dx.doi.org/10.1053/ajkd.2003.50029

[15] Israel, M. (1986) Depression in Dialysis Patients: A Review of Psychological Factors. Canadian Journal of Psychiatry, 31, 445-451. 
[16] Wuerth, D., Finkelstein, S.H. and Finkelstein, F.O. (2005) The Identification and Treatment of Depression in Patients Maintained on Dialysis. Seminars in Dialysis, 18, 142-146. http://dx.doi.org/10.1111/j.1525-139X.2005.18213.x

[17] Hedayati, S.S., Minhajuddin, A.T. and Toto, R.D. (2009) Prevalence of Major Depressive Episode in CKD. American Journal of Kidney Disease, 54, 424-432. http://dx.doi.org/10.1053/j.ajkd.2009.03.017

[18] Palmer, S.C., Vecchio, M., Craig, J.C., et al. (2013) Association between Depression and Death in People with CKD: A Meta-Analysis of Cohort Studies. American Journal of Kidney Disease, 62, 493-505.

http://dx.doi.org/10.1053/j.ajkd.2013.02.369 